\title{
STRATEGI PENANGKALAN \& PENANGGULANGAN RADIKALISME MELALUI CULTURAL REINFORCEMENT MASYARAKAT JAWA TENGAH
}

\author{
Arif Hidayat, Laga Sugiarto \\ Fakultas Hukum, Universitas Negeri Semarang, Semarang \\ arifardat@gmail.com
}

\begin{abstract}
Abstrak
Artikel ini akan mendiskusikan alternatif penangkalan dan penanggulangan radikalisme di era disrupsi dan keterbukaan informasi. Radikalisme pada hakikatnya adalah persoalan konflik budaya dalam masyarakat yang plural, sehingga perlu identifikasi, revitalisasi dan reaktualisasi budaya hukum dan kearifan lokal guna menangkal dan menanggulanginya. Penelitian ini merupakan penelitian hukum kualitatif, dengan pendekatan socio-legal. Subjek dalam penelitian ini adalah stakeholders masyarakat adat sedulur sikep (Kudus \& Pati), masyarakat budaya Surakarta maupun komunitas pondok pesantren API Magelang. Penelitian ini menemukan bahwa kearifan lokal sebagai sistem kepercayaan, nilai-nilai, dan kebudayaan yang merupakan sub dari budaya hukum adalah kekayaan sekaligus kekuatan (natural resources) untuk dijadikan bingkai kebangsaan sebagai instrumen dalam menciptakan kedamaian, kebersamaan, persatuan, dan keutuhan bangsa. Budaya hukum dan kearifan lokal di Jawa Tengah, memiliki tiga epicentrum, yaitu: komunitas pesantren, komunitas masyarakat adat, dan komunitas masyarakat budaya. Komunitas pesantren merupakan komunitas keagamaan sebagai institusi sosial yang terdiri dari kyai, santri, wali santri dan alumni dalam pola pendidikan, dengan materi dan metode humanistik tertentu untuk mengajarkan nilai-nilai kearifan sehingga menghasilkan perilaku yang santun, sabar, toleran dengan mengedepankan nalar, kasih sayang dan keteladanan. Komunitas masyarakat adat (indigenous peoples) adalah kelompok masyarakat atau suku bangsa yang memiliki asal-usul leluhur (secara turun temurun) di wilayah geografis tertentu, serta memiliki nilai, keyakinan, ekonomi, politik, dan budaya sendiri yang khas. Adapun komunitas masyarakat budaya (cultural society) adalah komunitas sosial yang memiliki akar identitas kuat dan menciptakan rasa memiliki yang kuat (community ownership and identity), dicirikan adanya daya pemikiran kritis (critical thinking); dan daya pemikiran mandiri (independent thinking). Penelitian ini merekomendasikan perlunya pendekatan integratif dan komprehensif melalui cultural reinforcement, baik soft approach dalam mengkampanyekan pemikiran Islam "rahmatan lil'alamin", maupun hard approach yang terukur (akurat, presisi dan valid).
\end{abstract}




\title{
Kata Kunci: Budaya hukum; Kearifan Lokal; Radikalisme \\ STRATEGY OF RADICALISM DETERMINATION \& MANAGEMENT THROUGH CULTURAL REINFORCEMENT CENTRAL JAVA COMMUNITIES
}

\author{
Arif Hidayat, Laga Sugiarto \\ Faculty of Law, Semarang State University, Semarang \\ arifardat@gmail.com
}

\begin{abstract}
This article describes the alternative efforts to counter and overcome radicalism in the era of disruption, and information disclosure. In essence, radicalism is a matter of cultural conflict in a pluralistic society, so to counteract and overcome it requires identification, revitalization and re-actualization of the legal culture and local wisdom. This research is a qualitative legal research, with a socio-legal approach. The subjects in this study were stakeholders: the indigenous peoples of Sedulur Sikep (Kudus \& Pati), the Surakarta cultural community and the API Magelang Islamic boarding school community. This research found that local wisdom as a system of beliefs, values, and culture which is a sub of legal culture is wealth as well as strength (natural resources) as a national frame as an instrument in creating peace, togetherness, unity, and integrity of the nation. The legal culture and local wisdom in Central Java, has three "epicentrum", namely: "pesantren" community, indigenous community, and cultural community. Pesantren community, is a religious community as a social institution consisting of kyai, santri, santri guardians and alumni in educational patterns, with certain humanistic materials and methods to teach the values of wisdom so as to produce polite, patient, tolerant behavior by promoting reason, love, and exemplary. Indigenous peoples are groups of people or ethnic groups that have ancestral origins (hereditary) in certain geographical areas, as well as having their own values, beliefs, economics, politics, and culture. The cultural community (cultural society) is a social community that has strong identity roots and creates a strong sense of ownership (community ownership and identity), characterized by having critical and independent thinking. This study recommends the need for an integrative and comprehensive approach through cultural reinforcement, both a soft deradicalization in campaigning for Islamic thought of "rahmatan lil'alamin", as well as a measured hard deradicalization (accurate, precise and valid).
\end{abstract}

Keywords: Legal Cultur; Local Wisdom; Radicalism 


\section{A. PENDAHULUAN}

Konflik hukum dan masalah ketidakpatuhan terhadap hukum, memerlukan penyelesaian kultural, dan tidak hanya mengutamakan pemaksaan dengan menerapkan ketegasan sanksi. Persoalan mendasarnya adalah mengenai keyakinan dan kesadaran masyarakat yang merujuk ke perangkat budaya yang berbeda, dari postulat yang diambil sebagai premis kebijakan negara. Budaya hukum merupakan suatu konkritisasi nilai-nilai yang dianut (sebagian besar) masyarakat, sebagai satu kesatuan sistem hukum, selain substansi dan struktur hukum ${ }^{1}$.

Pemberlakuan Undang-Undang Nomor 5 Tahun 2018 Tentang Perubahan Atas UU No. 15 Tahun 2003 Tentang Penetapan Perpu No. 1 Tahun 2002 Tentang Pemberantasan Tindak Pidana Terorisme Menjadi Undang-Undang (UU Antiterorisme) menjadi babak baru dalam penanggulangan terorisme yang lebih komprehensif, meliputi pencegahan, penegakan hukum atau penindakan (pemberantasan, penanggulangan), dan perlindungan termasuk pemulihan korban dan kompensasinya, kelembagaan dan pengawasan. UU Antiterorisme memberi otoritas yang lebih besar kepada LPSK, kepolisian, kejaksaan, kehakiman, maupun BNPT, dan lembaga terkait lainnya. Selain itu juga adanya tim pengawas yang akan dibentuk DPR RI untuk memonitor dan mengevaluasi kerja lembagalembaga tersebut. Kunci efektifitasnya adalah sinergitas semua pihak, baik pemerintah (kementerian dan lembaga) yang memiliki kewenangan di tingkat nasional maupun daerah, berkolaborasi dengan segenap masyarakat dan tokohtokoh masyarakat. Namun demikian, sejumlah pihak mengkhawatirkan adanya pelanggaran HAM dalam upaya penanggulangan terorisme, sebagaimana jajak pedapat kompas berikut.

${ }^{1}$ Lihat Lawrence Meir Friedman. The Legal System: A Social Sciences Perspective, (New York: Russell Sage Foundation, 1975). 


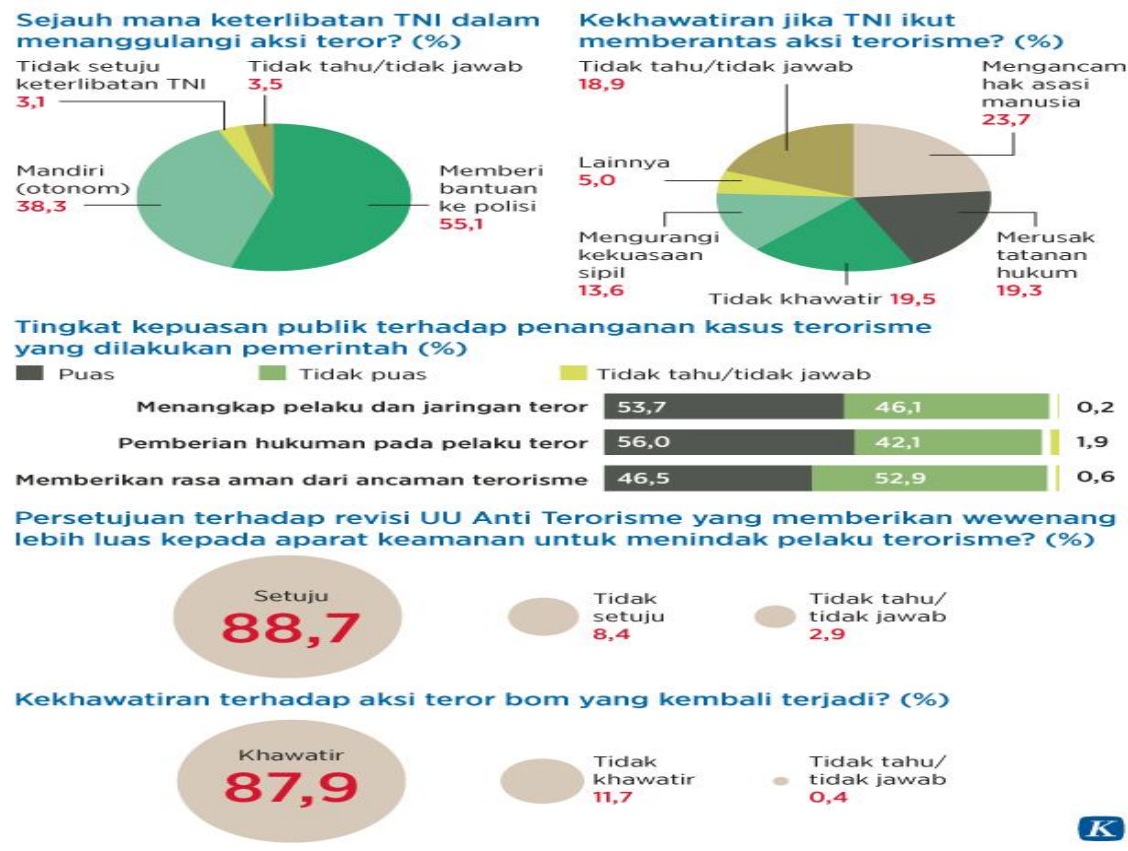

Jajak Pendapat Kompas , 05/06/2017

Radikalisme merupakan gangguan, ancaman, tantangan dan hambatan nasional, dengan berbagai motif, diantaranya ${ }^{2}$ : (i) kesukuan, nasionalisme/separatisme (etnicity, nationalism /separatism); (ii) kemiskinan, kesenjangan dan globalisasi (poverty, economic disadvantage, and globalisation); (iii) tidak adanya demokrasi; (iv) pelanggaran harkat kemanusiaan (dehumanisation); dan eksklusifime agama. Data Kementerian Sosial, menyebutkan bahwa berdasarkan hasil asesmen terhadap 152 WNI yang dideportasi dari berbagai negara (Turki, Hongkong, Taiwan, Jepang, Brunai Darussalam), dalam periode 23 Januari-23 April 2017, di Panti Sosial Marsudi Putra Handayani (PSMP) Kemensos, diperoleh beberapa informasi penting, diantaranya: (i) 90\% deportan memiliki keinginan untuk hijrah ke negeri Syam karena memiliki keyakinan dengan hadits Nabi yang mengatakan bahwa di akhir zaman negeri yang aman dan diberkahi adalah negeri Syam; (ii) menginginkan hidup lebih baik; (iii) relasi sosial kurang baik, rata-rata menunjukkan sikap diam, dingin, menarik diri, cuek, kurang komunikatif; dan (iv) kecewa tak

\footnotetext{
${ }^{2}$ Baca Bambang, Pranowo, Orang Jawa Jadi Teroris, (Jakarta: Pustaka Alfabet, 2011).
} 
dapat hijrah ke Suriah, namun mereka menerima karena sudah menjadi qodarullah (kehendak Alloh). ${ }^{3}$

Radikalisme merupakan faham atau aliran radikal dalam politik yang menginginkan perubahan atau pembaharuan sosial dan politik dengan cara kekerasan atau drastis. ${ }^{4}$ Radikalisme merupakan pandangan mengenai keinginan melakukan perubahan radikal sesuai dengan interpretasi agama dan ideologi yang dianut melalui kekerasan fisik ataupun kekerasan simbolik, bahkan sampai pada bunuh diri menuju kebermaknaan hidup yang diyakininya. ${ }^{5}$ Hulu dari radikalisme adalah fundamentalisme yaitu radikalisasi paham keagamaan komunitas yang mengkonstruksi makna salafisme radikal yang eksklusif dan cenderung ekstrim (merasa paling benar, dan menyesatkan orang lain). ${ }^{6}$ Adapun hilir dari radikalisme adalah aksi terorisme (faham mengenai pilihan penggunaan cara-cara kekerasan yang menimbulkan ketakutan dan ancaman (intangible threats) sebagai cara yang sah untuk mencapai suatu tujuan tertentu yang biasanya mengatasnamakan suatu agama atau ideologi). ${ }^{7} \quad$ Terorisme merupakan kejahatan transnasional (transnational crime) dan terorganisir (organized of crime) terhadap kemanusiaan, perdamaian dan keamanan nasional serta merugikan kesejahteraan masyarakat, sehingga dikategorikan sebagai kejahatan luar biasa (extra ordinary crime), sehingga membutuhkan pola penanganan luar biasa (extra ordinary measure). ${ }^{8}$

\footnotetext{
${ }^{3}$ Dini Fajar Yanti, 2017, “Sistem Penanganan Radikalisme Bidang Sosial: Suatu Pendekatan Penanganan Radikalisme oleh Kementerian Sosial”, Melalui http://puspensos.kemsos.go.id/home/br/554. [12/06/2019].

${ }^{4}$ Djaka Soetapa,. “Asal-usul Gerakan Fundamentalisme”, Jurnal Ulumul Qur'an, Vol. IV, No. 3, 1993.

5 Baca Abu Rokhmad, "Radikalisme Islam dan Upaya Deradikalisasi Paham Radikal", Jurnal Walisongo, Vol. 20, No. 1, Mei 2012. Lihat juga Azyumardi Azra., "Toleransi Agama dalam Masyarakat Majemuk: Perspektif Muslim Indonesia, " dalam Elza Peldi Taher, Merayakan Kebebasan Beragama, (Jakarta: Kompas-ICRP, 2009).

${ }^{6}$ Lihat Syamsul Arifin,. "Radikalisasi Paham Keagamaan Komunitas Pesantren", Jurnal AlMawarid, Vol. 12, No. 1 Januari - Juni (2009): 41-53.

${ }^{7}$ Baca Syamsul Bakri, 2004. "Islam dan Wacana Radikalisme Agama Kontemporer," Jurnal Dinamika, Vol. 3 No. 1, Januari 2004. Lihat juga Petrus Reinhard Golose, Deradikalisasi Terorisme: Humanis, Soul Approach, dan Menyenuh Akar Rumput (Jakarta: Yayasan Pengembangan Kajian Ilmu Kepolisian, 2009), hlm. 38.

${ }^{8}$ Baca Muh. Khamdan, "Rethinking Deradikalisasi: Konstruksi Bina Damai Penanganan Terorisme", Jurnal ADDIN, Vol. 9, No. 1, Februari 2015, hlm. 181-204; Baca juga Farid Septian, "Pelaksanaan Deradikalisasi Narapidana Terorisme di Lembaga Pemasyarakatan Kelas I Cipinang", Jurnal Kriminologi Indonesia, Vol. 7, No. 1, Mei 2010.
} 
Menjamurnya kelompok-kelompok Islam radikal, baik skala lokal [Front Pemuda Islam Surakarta (FPIS) di Surakarta dan Front Thariqah Jihad (FTJ) di Kebumen], skala nasional [seperti Front Pembela Islam (FPI), Hizbut Tahrir Indonesia (HTI), Lasykar Mujahidin, Ikhwanul Muslimin Indonesia], dan bahkan sampai skala internasional seperti gerakan Salafi, Jamaah Ansharud Daulah (JAD), dan Hizbut Tahrir turut mereduksi sebagian wajah keberagamaan masyarakat Indonesia (Jawa Tengah), yang santun, toleransi, dan penuh tepo seliro. Hal ini sedikit demi sedikit mempengaruhi watak kebaragamaan masyarakat yang jauh dari ajaran dari leluhur. ${ }^{9}$

Pada hakikatnya, radikalisme dan terorisme adalah persoalan konflik budaya dalam suatu masyarakat nasional yang bersifat plural secara kultural ${ }^{10}$, sehingga pencegahan, baik sebagai strategi pencegahan awal (preventive) dan aksi dadakan (pre-emptive) melalui budaya hukum dan kearifan local (local wisdom) merupakan solusi terbaik dalam menangkal radikalisme yang senantiasa berkembang di Indonesia, terutama di daerah Jawa Tengah yang telah menjadi "zona merah" bagi perkembangan terorisme. Berbagai cara masih sangat mungkin dijadikan sebagai jalan untuk mengkompromikan paham keagamaan untuk bisa berjalan berdampingan satu dengan lainnya. Kearifan lokal yang merupakan sub dari budaya hukum adalah kekayaan sekaligus kekuatan untuk menjadi instrumen dalam mencairkan suasana dalam hidup bermasyarakat, berbangsa dan bernegara agar lebih baik dan harmoni satu dengan lainnya. ${ }^{11}$

Pencegahan radikalisme, baik berupa kesiapsiagaan nasional, kontra radikalisasi dan deradikalisasi sangat diperlukan mengingat radikalisme telah masuk ke setiap lini kehidupan dan ke semua kalangan masyarakat, baik orang tua, remaja, kaum perempuan bahkan anak-anak. Misalnya, Laila Khalid (telah dua kali membajak pesawat), Dian Yulia Novi (diduga akan melakukan bom bunuh

9 Lihat Syamsul Ma`arif, dkk.. "Peningkatan Daya Tangkal Masyarakat Jawa Tengah Terhadap Radikalisme Melalui Kearifan Lokal”, Penelitian FKPT-BNPT 2018.

${ }^{10}$ Baca Azyumardi Azra, "Memahami Gejala Fundamentalisme", Jurnal Ulumul Qur'an, No. 3 Vol. IV, 1993.

${ }^{11}$ Sartini, 2004. "Menggali Kearifan Lokal Nusantara: Sebuah Kajian Filsafat", Jurnal Filsafat, Vol. 3, No. 7, (2004): 97-111. 
diri di istana kepresidenan), Ika Puspitasari alias Salsabila mantan TKI dari hongkong, Jumiatun Muslim alias Umi Delima istri dari pelaku terorisme Santoso, bahkan Tini Susanti alias Umi Fadel (anggota MMI) yang tertangkap pada saat tengah mengandung 8 bulan. $^{12}$

Platzdasch ${ }^{13}$ menyebutkan bahwa kondisi perubahan berpotensi melahirkan instabilitas sosial politik dan menimbulkan sejumlah konflik. Hal ini terbukti dalam perubahan era revolusi industri saat ini yang melahirkan ekspresi masyarakat (termasuk ekspresi keberagamaan yang trust claim) melalui medsos, (facebook, whatsapp, twitter, dan jejaring sosial lainnya). Fenomena tersebut, bahkan mengakibatkan konflik dan gesekan di tengah pluralitas pemahaman keagamaan sehingga menyulut hoax dan ujaran kebencian di antara kelompok masyarakat. Kondisi ini menyemaikan bibit-bibit radikalisme, merembes lebih meluas melalui dunia maya, bahkan menjadi ancaman serius bagi masa depan generasi muda dan kualitas pendidikan di Indonesia. Peneliti LIPI Anas Saidi menyatakan bahwa radikalisme ideologi telah merambah ke dunia kampus dan berpotensi memecah belah bangsa, ditunjukkan dengan data $25 \%$ siswa dan $21 \%$ guru menyatakan Pancasila tidak lagi relevan. ${ }^{14}$ Hal yang sama juga dinyatakan oleh Alamsyah M. Dja'far, peneliti Wahid Institute yang menyebutkan adanya penguatan sikap intoleransi di sekolah. ${ }^{15}$

Muhammad Adnan, peneliti Departemen Politik dan Pemerintahan FISIP Undip Semarang merilis hasil penelitian (2017) mengenai darurat intoleransi di Wilayah Jawa Tengah, bahwa 8,7\% guru agama menganggap konsep khilafah atau Negara Islam tepat diterapkan di Indonesia; dan 4,3\% guru agama menganggap

12 Lihat Editorial, Jalan Damai Majalah Pusat Media Damai BNPT, (BNPT, Edisi 4./No.2/Mei/2017), Baca juga Editorial, Merubah Benci Menjadi Cinta, Majalah Pusat Media Damai BNPT, Edisi 8./No.2/September 2017, hlm 11.

13 Bernhard Platzdasch, "Islamism in Indonesia: Politics in the Emerging Democracy". Singapore: Institute of Southeast Asian Studies, Volume 42 Issue 2, Merle C. Ricklefs, 2009, hlm. xxxvii, 411.

14 Prima Gumilang, 2016, "Radikalisme Ideologi Menguasai Kampus", Melalui http://cnnindonesia.com/nasional/20160218193025-12-111927/radikalisme-ideologi-menguasaikampus. [12/06/2019]. [12/05/2019]. 
Pancasila bukan lagi ideologi yang tepat diterapkan di Indonesia. Sebelumnya, sebuah yayasan pendidikan di Kabupaten Semarang pernah memecat 13 guru karena mengajarkan paham radikal. ${ }^{16}$ Pada tanggal 30 Januari 2018, diseminasi hasil penelitian literatur keislamanan Generasi Milenial (2018), yang diselenggarakan Pascasarjana UIN Yogyakarta bersama PPIM UIN Syarif Hidayatullah Jakarta, ISNU, dan PusPIDep Yogyakarta, mencatat bahwa Solo merupakan kota yang banyak melahirkan penerbit buku islamisme dan jihadisme, paralel dengan perkembangan radikalisme di kota tersebut. ${ }^{17}$

Melihat kenyataan tersebut, lebih-lebih pada wilayah Jawa Tengah yang menurut Kasubdit Kewaspadaan Badan Nasional Penanggulangan Terorisme sudah masuk pada zona merah penyebaran radikalisme dan terorisme. ${ }^{18}$ Ditambah lagi dengan laporan tahunan hasil penelitian dari Lembaga Studi Sosial dan Agama (eLSA) bahwa, pada tahun 2016, terdapat peningkatan tindak intoleransi di Jawa Tengah. Padahal intoleransi, sebagaiamana hipotesis SETARA Institute, merupakan titik awal dari terorisme. ${ }^{19}$ Maka, semua komponen masyarakat harus bertanggung jawab dan perlu mencari solusi efektif yang bisa ditawarkan untuk memutus mata rantai radikalisme di Indonesia. Guna mengantisipasi masuknya radikalisme dalam dunia pendidikan, pemerintah melalui Kementrian Pendidikan Nasional sebenarnya telah melakukan antisipasi dengan menekankan kurikulum yang berbentuk nilai-nilai nasionalisme dan kebangsaan pada peserta didik. Perubahan ini tidak hanya dilakukan di perguruan tinggi, namun juga di jenjang sekolah dasar hingga menengah. ${ }^{20}$

Hasil survey yang dilakukan Badan Nasional Penanggulangan Terorisme (BNPT) tahun 2018 menyatakan bahwa kearifan lokal dapat menangkal

${ }^{16} \mathrm{http} / /: w w w . d u t a i s l a m . c o m / 2017$ [12/06/2019].

17 Agus Utantoro, 2018, "Solo Kota Paling Banyak Lahirkan Penerbit Buku Konten Radikal", Melalui http//:www.mediaindonesia.com/news/read/143060/Solo-kpta-paling-banyaklahirkan-penerbit--buku-content-radikal/2018. [12/06/2019].

18 Dede Rosyadi, 2016, Jateng disebut salah satu daerah rawan radikalisme dan terorisme, Melalui https://www.google.co.id/amp/m.merdeka.com/amp/peristiwa/jateng-disebut-salah-satudaerah-rawan-radikalisme-dan terorisme.html. [12/06/2019].

${ }^{19}$ Ahmad Said Hasani, "Radikalisme Agama Dalam Perspektif Hukum Islam” Universitas Islam Negeri Raden Intan Lampung: Jurnal Al-'Adalah, Vol. 12, No. 1, 2015, hlm. 593-610.

${ }^{20}$ HR. Tilaar, Manifesto Pendidikan Nasional, (Jakarta: Kompas, 2005), hlm. 17. 
radikalisme. Kepercayaan masyarakat bahwa kearifan lokal sangat menentukan untuk mereduksi paham-paham radikalisme dan seluruh paham negatif berada pada skor kategori tinggi, yaitu $63,60 .^{21}$ Survei tersebut menggunakan metode kualitatif dan kuantitatif. Secara kualitatif melibatkan diskusi dan wawancara bersama pemda, tokoh budaya, tokoh masyarakat, tokoh agama, dan akademisi. Sedangkan kuantitatif melalui penyebaran kuesioner kepada 450 responden di 32 provinsi dengan total 14.400 responden seluruh Indonesia. Minimnya dokumentasi dan pemahaman utuh masyarakat mengenai budaya hukum dan kearifan lokal menyulitkan inventarisasi kearifan lokal sekaligus transfer of knowledge.

Penelitian ini menjadi penting didasarkan pada beberapa alasan. Pertama, optimalisasi pelaksanaan Undang-Undang Nomor 5 Tahun 2018 akan dapat efektif apabila kebijakan turunannya menempatkan budaya hukum dan kearifan lokal, melalui pelibatan stakeholders masyarakat, baik masyarakat adat, masyarakat budaya, maupun komunitas pesantren dalam penyusunan strategi, mulai dari perencanaan, pengorganisasian, pelaksanaan dan pengawasan. Kedua, belum adanya ketentuan hukum khusus terkait pondok pesantren maupun komunitas mayarakat lokal (masyarakat adat \& masyarakat budaya) dalam partisipasinya mencegah dan menanggulangi radikalisme. Ketiga, adanya potensi pondok pesantren mengajarkan faham radikalisme berbasis agama dan melunturnya budaya toleransi. Keempat, adanya potensi pelanggaran HAM dalam upaya penanggulangan terorisme. Kelima, kurangnya frekuensi dan intensitas sosialisasi yang dilakukan oleh pemerintah mengakibatkan program pencegahan dan penanggulangan radikalisme melalui budaya hukum dan kearifan lokal yang telah direncanakan tidak dipahami dan didukung oleh masyarakat setempat. Keenam, minimnya dokumentasi dan pemahaman utuh masyarakat mengenai budaya hukum dan kearifan lokal menyulitkan inventarisasi kearifan lokal sekaligus transfer of knowledge. Berdasarkan realitas tersebut, maka penelitian ini akan mengidentifikasi eksistensi budaya hukum \& kearifan lokal yang berkembang dalam kehidupan masyarakat di Jawa Tengah, dan merumuskan peran

\footnotetext{
${ }^{21}$ https://www.bnpt.go.id/ [12/06/2019].
} 
dan fungsi budaya hukum \& kearifan lokal masyarakat Jawa Tengah sebagai strategi penangkalan dan penanggulangan radikalisme.

\section{B. METODE PENELITIAN}

Studi ini merupakan penelitian hukum kualitatif ${ }^{22}$, menggunakan pendekatan socio-legal ${ }^{23}$. Subjek dalam penelitian ini adalah stakeholders masyarakat adat (indigenous peoples) Sedulur Sikep (Kudus \& Pati), masyarakat budaya (cultural society) Surakarta maupun komunitas pondok pesantren API Magelang, serta beberapa tokoh intelektual di Jawa Tengah yang expert di bidang anti radikalisme dan terorisme. Data data primer dan data sekunder dikumpulkan melalui pengamatan, wawancara, focus group discussion, dan teknik dokumentasi. Pemeriksaan keabsahan data menggunakan teknik cross check triangulasi ${ }^{24}$, dan dianalisis menggunakan teknik kualitatif induktif ${ }^{25}$.

\section{PEMBAHASAN}

\section{Eksistensi Budaya Hukum dan Kearifan Lokal dalam Kehidupan Masyarakat di Jawa Tengah}

Eksistensi budaya hukum \& kearifan lokal yang berkembang dalam kehidupan masyarakat di Jawa Tengah dibagi ke dalam tiga epicentrum, yaitu komunitas pesantren; komunitas masyarakat adat, dan komunitas masyarakat budaya. Komunitas pesantren, adalah komunitas keagamaan sebagai institusi sosial yang terdiri dari kyai, santri, wali santri dan alumni dalam pola pendidikan, dengan materi dan metode humanistik tertentu untuk mengajarkan nilai-nilai kearifan sehingga menghasilkan perilaku yang santun, sabar, toleran dengan mengedepankan nalar, kasih sayang dan keteladanan. Komunitas masyarakat adat (indigenous peoples) adalah kelompok masyarakat atau suku

${ }^{22}$ Suharsimi Arikunto, Prosedur Penelitian Suatu Pendekatan, (Jakarta: Rineka Cipta, 1993), hlm. 23.

${ }^{23}$ Satjipto Rahardjo, Ilmu Hukum, (Bandung: Offset Alumni, 1985), hlm. 80-81. Metode pendekatan socio-legal dipergunakan untuk menganalisis hukum (ilmu hukum) dan perilakuperilaku dalam masyarakat (ilmu sosial) dalam penangkalan dan penanggulangan radikalisme.

${ }^{24}$ Burhan Bungin, Metode Penelitian Kualitatif: Aktualisasi Metodologis ke Arah Varian Kontemporer, (Jakarta: Raja Grafindo Persada, 2001), hlm. 18.

${ }^{25}$ Ronny Hanitijo Soemitro, Metodologi Penelitian Hukum dan Jurimetri. Ghalia Persada, Jakarta, 1990, hlm. 116. Lihat juga Soerjono Soekanto, Pengantar Penelitian Hukum, (Jakarta: UI Press, 2001), hlm. 250. 
bangsa yang memiliki asal-usul leluhur (secara turun temurun) di wilayah geografis tertentu, serta memiliki nilai, keyakinan, ekonomi, politik, dan budaya sendiri yang khas. Adapun komunitas masyarakat budaya (cultural society) adalah komunitas sosial yang memiliki akar identitas kuat dan menciptakan rasa memiliki yang kuat (community ownership and identity). Ciri khusus dari masyarakt budaya adalah: (i) daya pemikiran kritis (critical thinking); dan (ii) daya pemikiran mandiri (independent thinking).

Eksistensi pondok pesantren (API) di tengah masyarakat merupakan sub kultur, dengan tiga elemen dasar, yaitu: pola kepemimpinan pesantren yang mandiri (tidak terkooptasi oleh negara); (ii) kitab-kitab rujukan umum yang selalu digunakan dari berbagai abad (klasik); dan sistem nilai (value system) yang digunakan adalah bagian dari masyarakat luas. Tanggung jawab pesantren sebagai agen perubahan (agent of change) dan sekaligus sebagai agen pewarisan budaya (agent of conservative), untuk menyemai nilai-nilai kedamaian, persahabatan dan kemanusiaan. Pendidikan pesantren merupakan pendidikan akhlak atau pendidikan karakter untuk menanamkan (habituation), mengetahui (knowing), mencintai (loving), dan melakukan (doing) kebaikan. Pendidikan pesantren terbukti mampu menopang budaya kosmopolitan dengan mengajarkan: (i) inklusivisme, keterbukaan diri terhadap unsur positif dari luar dan berusaha mengembangkannya secara kreatif; (ii) humanisme, apresiasi yang tinggi terhadap potensi dan nilai dasar kemanusiaan; (iii) toleransi, kebesaran jiwa dalam menyikapi perbedaan pendapat; dan (iv) kebebasan (demokrasi) dalam berpendapat dan berpikir

Eksistensi masyarakat adat (Sedulur Sikep), merupakan pranata sosial khas yang dilandasi nilai dan moralitas perdamaian yakni ketaatan terhadap aturan (hukum) dan prinsip hidup yang dipegang (moral), diyakini dan diimplementasikan bersama untuk mengembangkan hal-hal baik dalam jalinan keterhubungan atau komunikasi dan interaksi dalam kehidupan berbangsa dan bernegara. Etika moral tersebut dilandasi tiga nilai utama dalam kehidupan, 
yakni keadilan, kejujuran dan kebenaran. Keberadaan nilai-nilai Sedulur Sikep melekatkan konstruksi identitas keyakinannya pada pertanian, di mana kohesi sosial didasarkan pada apa yang mereka sebut sebagai konsep "totocoro sikep". Karakter identitas Sedulur Sikep, secara sosial-budaya tertuang dalam konstruksi diskursif (menjunjung tinggi jejagongan, ngakoni, blak-blakan, toleransi \& egaliter), yang lahir lahir dari keteguhan anggota komunitas untuk menjalankan ajaran-ajaran sikep secara konsisten. Politik kenegaraan (kepangrehprajaan) dan tata laku hidup keseharian Sedulur Sikep diabstraksikan dalam Kepek Pandoming Laku Gesang (pedoman kehidupan), di mana bentuk kenegaraan yang ideal adalah sebuah negara beserta rakyatnya yang memperhatikan keutamaan ilmu pengetahuan, berdasarkan dua kriteria taitu: (i) kemajuan negara didasarkan pada kecendekiawanan; (ii) serta kerukunan yang disandarkan pada kesetiaan warga negara kepada negaranya. Keberagamaan atau ageman (religiusitas) warga Sedulur Sikep diwujudkan dalam tiga dimensi yakni keyakinan, peribadatan, dan perilaku. Manifestasinya terlihat dalam prinsip sosial kemasyarakatan (etis-sosiologis) yang menganggap semua orang adalah saudara, sinten mawon kulo aku sedulur, dan berperilaku harmonis dengan alam sekitarnya (hamemayu hayuning bawana). Budaya hukum dan kearifan lokal masyarakat adat Sedulur Sikep bewujud prinsip-prinsip moral berupa sikap hormat terhadap alam (respect for nature), sikap tanggung jawab terhadap alam (moral responsibility for nature), solidaritas kosmis (cosmic solidarity), prinsip kasih sayang dan kepedulian terhadap alam (caring for nature), prinsip tidak merugikan alam (no harm), prinsip hidup sederhana dan selaras dengan alam; prinsip keadilan; prinsip demokrasi; dan prinsip integritas moral.

Eksistensi masyarakat budaya (Kasepuhan Surakarta), merupakan pranata sosial khas yang memiliki akar identitas dan "rasa memiliki" yang kuat terhadap warisan budaya. Masyarakat budaya memiliki kesadaran terhadap identitasnya sendiri dan cenderung dinamis mencari inisiatif-inisiatif baru yang 
relevan dengan lapisan kultur masyarakatnya. Karakteristik identitas masyarakat budaya yang spesifik merupakan simbol yang menghubungkan kehidupan antar generasi (sense of identity), sehingga diakui dan diwariskan secara turun temurun antar generasi (constantly recreated). Interaksi dan akulturasi Islam (Walisongo, Kerajaaan Demak \& Mataram Islam), budaya Jawa (Majapahita), budaya Eropa (kolonial Belanda), dan budaya Tionghoa dalam masyarakat budaya (Kasepuhan Surakarta) mempersyaratkan kesesuaian dengan hak asasi manusia secara universal, baik berupa kebiasaan maupun ekspresi. Warisan budaya tersebut berupa: (i) warisan benda atau pusaka ragawi (tangible heritage) berupa Jalan Slamet Riyadi, Benteng Vestenburg, Kampung Batik Kauman, Masjid Ageng Karaton, Pasar Klewer, Museum Keraton Kasunanan Surakarta, Tugu Pemandengan, Gapura Gladak, Alun Alun Lor, Kompleks Pagelaran Sasana Sumewa, dan sebagainya sebagai hasil hasil cita rasa, dan karsa suatu bangsa yang menghasilkan identitas spesifik; dan pusaka non ragawi (intangible heritage), berupa tradisi oral bahasa, proses kreasi kemampuan dan pengetahuan, seni pertunjukan, festival, religi dan kepercayaan, kosmologi, sistem pembelajaran dan kepercayaan, maupun praktik-praktik kepercayaan, termasuk di dalamnya musik dan lagu, seni pertunjukan, kuliner tradisional.

\section{Peran dan Fungsi Budaya Hukum \& Kearifan Lokal Masyarakat Jawa} Tengah Sebagai Strategi Penangkalan dan Penanggulangan Radikalisme

Pendekatan multikultural merupakan alternatif solusi dalam penangkalan dan penanggulangan radikalisme dengan revitalisasi dan reaktualisasi budaya hukum dan kearifan lokal sebagai perekat kerukunan masyarakat dengan segenap perbedaannya (bhinneka tunggal ika). Output dari cultural reinforcement ini adalah tumbuhnya jiwa nasionalisme (NKRI), dan pengakuan terhadap Pancasila dan UUD $1945^{26}$. Karakteristik dasar budaya hukum dan kearifan lokal adalah sebagai: (i) penanda identitas sebuah komunitas; (ii) elemen perekat lintas warga; (iii) kesadaran dari dalam sehingga tidak bersifat

${ }^{26}$ Baca H.M. Laica Marzuki, "Kesadaran Berkonstitusi dalam Kaitan Konstitusionalisme”, Jurnal Konstitusi, Vol. 6, No. 3 (2009), hlm. 3-11. 
"memaksa"; (iv) pemberi warna kebersamaan sebuah komunitas; (v) pengubah pola pikir dan hubungan interaktif di atas pijakan common ground; dan (vi) pendorong proses apresiasi dan partisipasi, sekaligus pengurang anasir yang merusak integrasi sosial.

Peran budaya hukum dan kearifan komunitas masyarakat pesantren, masyarakat adat, dan masyarakat adat sangat diperlukan untuk menangkal dan menanggulangi radikalisme, mengingat adanya: (i) jaringan hubungan sosial (networks of social relations); (ii) rasa saling percaya (reciprocal trust); dan (iii) kemauan untuk saling membalas kebaikan (norm of reciprocity). Hal ini berpotensi untuk mengembangkan budaya kewarganegaraan (network of civic engagement) berbasis keadilan (equity), partisipasi sederajat, kolaborasi dan solidaritas. Budaya hukum dan kearifan lokal di Jawa Tengah memiliki beberapa fungsi, yaitu: edukatif; informatif, profetik, rekreatif, dan fungsi ilmiah atau akademis.

Komunitas masyarakat pesantren melatih kultur asosiasional untuk menampilkan Islam yang damai dan promotif terhadap pluralitas dan demokrasi, serta anti kekerasan (Rahmatan lil 'Alamin) ${ }^{27}$, melalui pengembangan lima karakter pesantren, yaitu: tawassuth (tidak memihak atau moderasi); tawazun (menjaga keseimbangan dan harmoni); tasammuh, (toleransi), tasyawwur (musyawarah); dan al-`adalah (adil dalam beraksi ataupun bereaksi). Paradigma fungsionalisasi budaya hukum dan kearifan lokal komunitas pesantren (edukasi \& enkulturasi) adalah: (i) upaya untuk membawa masyarakat kepada nilai ideologis dan faham agama yang benar dalam konteks kehidupan berbangsa dan bernegara di tengah tantangan propaganda ideologis; dan (ii) upaya menjaga agar masyarakat dapat memiliki otonomi dan independensi dengan menghidupkan kesalehan dan kecerdasan dalam kehidupan berbangsa dan bernegara.

27 Lihat Syamsul Arifin, 2009. "Radikalisasi..., Opcit.; Lihat juga Nella Sumika Puti, "Pelaksanaan Kebebasan Beragama di Indonesia (External Freedom)", Jurnal Dinamika Hukum, Vol. 11, No. 2, Mei (2011), hlm. 17-29. 
Komunitas masyarakat adat menjaga dan melestarikan kearifan lokalnya sebagai kekayaan budaya yang memuat kebijaksanaan, pandangan dan kearifan kehidupan sebagai referensi rujukan penyelesaian konflik, melalui pengembangan tiga karakter masyarakat adat, meliputi prinsip: (i) cinta dan setia kepada amanat leluhur, dan kearifan sesepuh (keteladanan); (ii) cinta dan hormat akan hukum \& pemerintahan yang dianggap sebagai "orang tua" \& sesepuh rohani; dan (iii) hormat dan setia pada dunia intelektual. Paradigma fungsionalisasi budaya hukum dan kearifan lokal masyarakat adat (edukasi \& enkulturasi) adalah: (i) upaya untuk memfungsikan masyarakat adat dalam menanamkan kesadaran nilai ideologis dan budaya "nenek moyang” yang benar dalam konteks kehidupan berbangsa dan bernegara di tengah tantangan propaganda ideologis; dan (ii) upaya menjaga agar masyarakat adat dapat memiliki ketahanan (resilience) dengan menghidupkan kesalehan dan kecerdasan dalam kehidupan berbangsa dan bernegara.

Komunitas masyarakat budaya memiliki kontribusi besar terhadap penciptaan modal sosial (social capital), dengan memperkuatkan jaringanjaringan sosial yang sangat menentukan ketahanan (resilience), baik secara individu maupun kolektif terhadap pengaruh faham radikal ${ }^{28}$. Masyarakat budaya memiliki kepekaan dan kemampuan menjaga kelangsungan budaya yang tumbuh berkembang sekian lama, dikenal, dipercayai, dan diakui sebagai elemen-elemen penting yang mampu menguatkan kohesi sosial di antara warga sebagai proses penguatan budaya (cultural reinforcement), melalui pengembangan empat karakter masyarakat budaya, berupa: (i) kebangggaan terhadap identitas (sense of identity); (ii) solidaritas (sense of solidarity); (iii) memperkuat rasa saling memiliki (sense of belonging); dan (iv) kebanggan sebuah bangsa (sense of pride). Paradigma fungsionalisasi budaya hukum dan kearifan lokal masyarakat budaya (kasepuhan) [(pelestarian (conserving), pembudayaan (culturing), dan sosialisasi (socializing)], adalah: (i) upaya untuk

${ }^{28}$ Baca Laila Kholid Alfirdaus, "Globalisation, Policy Transfer, And Global Governance: An Assessment in Developing Countries", Jurnal Politika, Vol. I, No. 1, April (2010), hlm. 11-23. 
membawa masyarakat kepada nilai etika Jawa sebagai kebijaksanaan hidup yang menuntut agar individu menyesuaikan diri dengan lingkungan masyarakat (ingkang bisa bawana bawani; prinsip keselarasan); dan (ii) upaya menjaga agar masyarakat dapat memenuhi kewajiban-kewajiban yang ditentukan oleh lingkungannya (anastiti mring wajibira tan gingsir) agar dapat menghidupkan kesalehan dan kecerdasan dalam kehidupan berbangsa dan bernegara.

\section{PENUTUP}

Eksistensi budaya hukum \& kearifan lokal yang berkembang dalam kehidupan masyarakat di Jawa Tengah (terbagi ke dalam tiga epicentrum, yaitu komunitas pesantren; komunitas masyarakat adat, dan komunitas masyarakat budaya), merupakan jatidiri dan akar identitas masyarakat Jawa Tengah yang memberikan kontribusi positif, baik sebagai modal sosial (social capital), maupun modal kultural (cultural capital), bagi keberlangsungan bangsa dan negara. Budaya hukum dan kearifan lokal dapat dijadikan sendi pembangunan karakter bangsa, untuk: (i) reorientasi penghayatan nilai-nilai Pancasila sebagai filosofi dan ideologi bangsa; (ii) mengisi keterbatasan perangkat kebijakan dalam mewujudkan nilai-nilai esensi Pancasila; (iii) memantapkan nilai etis dan etos dalam kehidupan berbangsa dan bernegara; (iv) menumbuhkan kesadaran terhadap nilai-nilai budaya bangsa; dan (v) meneguhkan integrasi bangsa dan negara.

Cultural reinforcement merupakan strategi penangkalan dan penanggulangan radikalisme yang efektif, dengan mengembangkan budaya kewarganegaraan (network of civic engagement) berbasis keadilan (equity), partisipasi sederajat, kolaborasi dan solidaritas. Budaya hukum dan kearifan lokal dengan beberapa fungsinya (edukatif; informatif, profetik, rekreatif, dan fungsi ilmiah atau akademis), berkontribusi membentuk struktur peradaban yang harmonis, penuh persaudaraan dan penghormatan terhadap keanekaragaman dengan mengarahkan orientasi kolektif masyarakat yang berakar dari identitas tradisinya. Budaya hukum dan kearifan lokal di Jawa Tengah. Peran budaya 
hukum dan kearifan lokal (komunitas masyarakat pesantren, masyarakat adat, dan masyarakat adat) sangat diperlukan untuk menangkal dan menanggulangi radikalisme, mengingat adanya: (i) jaringan hubungan sosial (networks of social relations); (ii) rasa saling percaya (reciprocal trust); dan (iii) kemauan untuk saling membalas kebaikan (norm of reciprocity). Hal ini berpotensi untuk mengembangkan budaya kewarganegaraan (network of civic engagement) berbasis keadilan (equity), partisipasi sederajat, kolaborasi dan solidaritas.

Bagi stakeholders budaya hukum dan kearifan lokal (pemangku pondok pesantren), khususnya para kyai hendaknya mengembangkan pemikiran Islam moderat (rahmatan lil'alamin) melalui pendekatan keagamaan yang humanistik. Pemangku masyarakat adat, hendaknya memanfaatkan potensi lokal berupa kepemimpinan adat, hukum dan sanksi adat, dan kearifan lokal lainnya untuk dijadikan narasi kontra radikalisme dalam menjaga hubungan masyarakat harmonis, baik homogen maupun heterogen. Adapun pemangku masyarakat budaya, hendaknya melakukan transformasi dekonstruktif terhadap kearifan lokal, dengan inventarisasi, redefinisi, reformulasi, dan transfer of knowledge antar generasi; Bagi pemerintahan pusat maupun daerah (eksekutif, legislatif, yudikatif) hendaknya mendorong percepatan pemenuhan kesejahteraan dan proses moderasi kehidupan keberagamaan dalam bingkai NKRI dalam segala sendi kehidupan, baik pendidikan, perekonomian, politik, sosial kemasyarakatan, maupun pertahanan dan keamanan, melalui ketentuan peraturan perundangundangan; Bagi kementerian dan lembaga terkait (Kementerian Agama) hendaknya mengoptimalkan pembinaan anti radikalisme dan terorisme maupun doktrin-doktrin kekerasan, serta penguatan orientasi keindonesiaan melalui jalur pendidikan (termasuk pondok pesantren), keluarga, kampanye, dan penyuluh agama. Kementerian Dalam Negeri, hendaknya meningkatkan pengawasan terhadap ideologi yang bertentangan dengan Pancasila dan mengoptimalkan sinergi jajarannya dengan segenap stakeholder untuk melekukan deteksi dini terhadap radikalisme. Kementerian Sosial, hendaknya mengoptimalkan upaya 
perlindungan sosial bagi korban terorisme, dan radikalisme yang memicu konflik sosial melalui penguatan akses kearifan lokal. Adapun BNPT, BIN, Kepolisian RI, hendaknya mengoptimalkan tindakan lebih tegas (hard approach) secara terukur akurasi, presisi dan validasinya untuk menindak kelompok-kelompok ekstrimis, teroris, fundamentalis dan radikalis, termasuk golongan anti NKRI dan Pancasila, mulai dari hulu ke hilir.

\section{DAFTAR PUSTAKA}

\section{BUKU}

Azyumardi Azra., "Toleransi Agama dalam Masyarakat Majemuk: Perspektif Muslim Indonesia", dalam Elza Peldi Taher, Merayakan Kebebasan Beragama, Jakarta: Kompas-ICRP, 2009.

Bambang, Pranowo, Orang Jawa Jadi Teroris, Jakarta: Pustaka Alfabet, 2011. Burhan Bungin, Metode Penelitian Kualitatif: Aktualisasi Metodologis ke Arah Varian Kontemporer, Jakarta: Raja Grafindo Persada, 2001.

HR. Tilaar, Manifesto Pendidikan Nasional, Jakarta: Kompas, 2005.

Lawrence Meir Friedman. The Legal System: A Social Sciences Perspective, New York: Russell Sage Foundation, 1975.

Petrus Reinhard Golose, Deradikalisasi Terorisme: Humanis, Soul Approach, dan Menyenuh Akar Rumput Jakarta: Yayasan Pengembangan Kajian Ilmu Kepolisian, 2009.

Ronny Hanitijo Soemitro, Metodologi Penelitian Hukum dan Jurimetri. Ghalia Persada, Jakarta, 1990.

Satjipto Rahardjo, Ilmu Hukum, Bandung: Offset Alumni, 1985

Soerjono Soekanto, Pengantar Penelitian Hukum, Jakarta: UI Press, 2001.

Suharsimi Arikunto, Prosedur Penelitian Suatu Pendekatan, Jakarta: Rineka Cipta, 1993.

\section{JURNAL}

Abu Rokhmad, "Radikalisme Islam dan Upaya Deradikalisasi Paham Radikal", Jurnal Walisongo, Vol. 20, No. 1, Mei 2012.

DOI: http://dx.doi.org/10.21580/ws.20.1.185

Ahmad Said Hasani, "Radikalisme Agama Dalam Perspektif Hukum Islam" Universitas Islam Negeri Raden Intan Lampung: Jurnal Al-'Adalah, Vol. 12, No. 1, 2015: 593-610. DOI: https://doi.org/10.24042/adalah.v12i1.238

Azyumardi Azra, "Memahami Gejala Fundamentalisme", Jurnal Ulumul Qur'an, No. 3 Vol. IV, 1993. 
Bernhard Platzdasch, "Islamism in Indonesia: Politics in the Emerging Democracy". Singapore: Institute of Southeast Asian Studies, Volume 42 Issue 2, Merle C. Ricklefs, 2009.

Djaka Soetapa, “Asal-usul Gerakan Fundamentalisme”, Jurnal Ulumul Qur'an, Vol. IV, No. 3, 1993.

Farid Septian, "Pelaksanaan Deradikalisasi Narapidana Terorisme di Lembaga Pemasyarakatan Kelas I Cipinang", Jurnal Kriminologi Indonesia, Vol. 7, No. 1, Mei 2010.

H.M. Laica Marzuki, "Kesadaran Berkonstitusi dalam Kaitan Konstitusionalisme", Jurnal Konstitusi, Vol. 6, No. 32009.

Laila Kholid Alfirdaus, "Globalisation, Policy Transfer, And Global Governance: An Assessment in Developing Countries", Jurnal Politika, Vol. I, No. 1, April 2010: 11-23.

Muh. Khamdan, "Rethinking Deradikalisasi: Konstruksi Bina Damai Penanganan Terorisme", Jurnal ADDIN, Vol. 9, No. 1, Februari 2015.

DOI: http://dx.doi.org/10.21043/addin.v9i1.612

Nella Sumika Puti, "Pelaksanaan Kebebasan Beragama di Indonesia External Freedom", Jurnal Dinamika Hukum, Vol. 11, No. 2, Mei 2011: 17-29.

Sartini, 2004. "Menggali Kearifan Lokal Nusantara: Sebuah Kajian Filsafat", Jurnal Filsafat, Vol. 3, No. 7, 2004: 97-111.

Syamsul Arifin,. "Radikalisasi Paham Keagamaan Komunitas Pesantren", Jurnal Al-Mawarid, Vol. 12, No. 1 Januari - Juni 2009: 41-53.

Syamsul Bakri, 2004. "Islam dan Wacana Radikalisme Agama Kontemporer," Jurnal Dinamika, Vol. 3 No. 1, Januari 2004.

\section{ARTIKEL}

Editorial, Jalan Damai Majalah Pusat Media Damai BNPT, BNPT, Edisi 4./No.2/Mei/2017,

Editorial, Merubah Benci Menjadi Cinta, Majalah Pusat Media Damai BNPT, Edisi 8./No.2/September 2017.

Syamsul Ma`arif, dkk.. "Peningkatan Daya Tangkal Masyarakat Jawa Tengah Terhadap Radikalisme Melalui Kearifan Lokal”, Penelitian FKPT-BNPT 2018.

\section{Internet}

Agus Utantoro, 2018, "Solo Kota Paling Banyak Lahirkan Penerbit Buku Konten Radikal", Melalui http//:www.mediaindonesia.com/news/read/143060/Solo-kpta-palingbanyak-lahirkan-penerbit--buku-content-radikal/2018. [12/06/2019].

Dede Rosyadi, 2016, "Jateng disebut salah satu daerah rawan radikalisme dan terorisme", https://www.google.co.id/amp/m.merdeka.com/amp/peristiwa/jatengdisebut-salah-satu-daerah-rawan-radikalisme-dan terorisme.html. [12/06/2019]. 
Dini Fajar Yanti, 2017, "Sistem Penanganan Radikalisme Bidang Sosial: Suatu Pendekatan Penanganan Radikalisme oleh Kementerian Sosial", Melalui http://puspensos.kemsos.go.id/home/br/554. [12/06/2019].

http//:www.dutaislam.com/2017 [12/06/2019].

http//:www.wahidinstitute.org/wi-id/indeks-opini/280-intoleransi-kaumpelajar.html. [12/05/2019].

https://www.bnpt.go.id/ [12/06/2019].

Prima Gumilang, 2016, "Radikalisme Ideologi Menguasai Kampus", Melalui http://cnnindonesia.com/nasional/20160218193025-12-

111927/radikalisme-ideologi-menguasai-kampus. [12/06/2019]. 